\title{
Faculty Input for Future Allocation of Scarce Educational Technology Resources
}

\author{
Linda D. Johnson \\ Argosy University \\ Orange, California, USA \\ Email: LJohnsonDBA [AT] gmail.com
}

\begin{abstract}
Faculty are major stakeholders in the California community college (CCC) system's ability to meet three primary mission objectives: increase student access, prepare students for transfer, and remain competitive. Educational technology (ET) can play a vital role in keeping the CCCs competitive, and modern learner-centric models rely heavily on faculty using ET, but ET is expensive. With 113 CCCs operating in an era of constrained budgets, the efficient allocation of scarce ET resources remains a challenge for the CCC system. Faculty input regarding their use of educational technology (ET) is invaluable, but no published empirical research explores the present and future use of ET by the CCC faculty. Therefore, the purpose of this study was to survey CCC faculty to determine their present ET hardware and software use, and their anticipated ET use five years in the future. Survey data from 655 active CCC faculty were analyzed using t-tests at the $p<.05$ threshold for statistical significance. Cohen's $D$ was used to describe the magnitude of anticipated change from current to future ET use. Results demonstrate that CCC faculty anticipate significant increases in their use of ET hardware and software over the next five years. Results also show that $42 \%$ of faculty had never been asked about their use of ET by an influencer, indicating that faculty are underutilized stakeholders in ET planning. Combined, these findings can be utilized by CCC administrative decision makers towards meeting their mission objectives by the efficient allocation of scarce ET resources.
\end{abstract}

Keywords - Educational technology, faculty, community college, higher education, resources, management, survey

\section{INTRODUCTION}

Educational technology (ET) is increasingly important to the financial sustainability of higher education (HE) in the United States. As in any large and evolving business, to ensure its long-term financial stability, the HE system must bear in mind its value proposition, resources, and efficiencies [1,2,3,4,5] and remain competitive. ET appears to be a reasonable solution to the many dilemmas facing colleges as ET is flexible, connects departments within a campus, and is scalable throughout the system [1]. However, ET is an expensive investment requiring hardware, software, infrastructure, maintenance, and training [4].

As gateways to higher education, US community colleges continue to increase student access capabilities. For the colleges to sustain this access, it is important to incorporate ET in a flexible and efficient manner that considers return on investment (ROI) and ensures that investment in ET complements rather than duplicates efforts [4,5]. Pathak and Pathak's [6] value chain model shows ET emerging as an "enabler as well as a creator of cost advantage and enhanced efficiency" [7, p.1183]. Upgrading and expanding ET is not only a necessary and expensive endeavor, but as a capital investment, ET decisions have long-term effects on ROI.

Bowen reminds us that "Educational institutions are good at adding things but not good at subtraction" [8, p.7]. In this spirit, Kirshstein and Wellman emphasized being aware of technology, capital, and maintenance costs, and that decision makers need "to understand where technology fits in, where technology works and does not work" [4, p.22]. In the context of allocating scarce resources, it is therefore equally important to determine both where ET needs will increase and where ET needs will not increase.

Faculty input is crucial towards meeting these goals. The involvement of faculty in operational activities and the importance of faculty input towards strategy development are central to Hutaibat's value chain for strategic management in higher education [9]. Underscoring the importance of stakeholder input, Zemsky held that, for colleges to become financially sustainable organizations, change is necessary and that this should be the business of faculty, as they are the content experts and practitioners of learning [10]. 
Undeniably, addressing value on investment (VOI) is important to a college's competitiveness [1]. From a VOI perspective, undergraduates increasingly prefer using mobile technologies in learning and expect their professors to use technology and to use it well $[11,12]$. Thus, determining what ET faculty use is important towards increasing VOI $[13,14]$ and ultimately towards improving HE's ability to compete [1]. Indeed, the data of Guidry and BrckaLorenz suggests the use of ET varies greatly within disciplines and even between iterations of the same course [12], highlighting the importance of faculty input to foster VOI and ROI. While some universities have surveyed their faculty regarding current use of ET [15, 16, 17, 18, 19, 20] or future use of ET [15, 16, 18, 19, 20], no published studies to date have focused on the community college system or provide empirical evidence upon which community colleges should base their ET expenditures.

The problem addressed in the present study is that we do not have a clear understanding of the ET hardware and software needs of community college faculty, neither in the present nor in the future. Without these data, the nation's community colleges cannot efficiently allocate scarce ET resources or adequately address the impact on its VOI and ROI The results of this study provide empirical evidence that California Community College (CCC) faculty anticipate statistically significant increases in their use of ET hardware (HW) and software (SW) over the next five years. The study also found a large percent of CCC faculty have never been asked for input regarding their use of ET.

\section{BACKGROUND}

The CCC system was chosen as the focus of this study for several reasons. The sheer size, broad mission, and mixed challenges experienced by this system are reflective of community colleges across the United States. Operating with a budget exceeding $\$ 8$ billion per year, the CCC system enrolls one-quarter of all community college students in the country. With current enrolments exceeding 2.2 million students, the CCCs are preparing for a forecasted increase of more than 350,000 students by 2023 [21].

In anticipation of this rapid growth, the CCC system is in the process of upgrading 40-year-old buildings and establishing an ET infrastructure capable of supporting increased access for students, data collection, and transferability needs. However, the CCC system needs will "likely exceed the state's anticipated financial capability" [22, p.9]. Almost a decade after the beginning of the Great Recession in 2007, the CCCs have received restoration of state funding to a pre2007 level, but the governor's 2017 budget forecasts a billion-dollar shortfall for infrastructure upgrades to support technology for the CCC system [22,23]. It is therefore imperative that the CCCs have empirical evidence from faculty regarding their present and future ET needs so that the CCCs can allocate their money wisely.

\section{THE PRESENT STUDY}

The 113 CCCs employ more than 60,000 faculty who use ET to communicate with students, deliver and grade coursework, monitor student progress, and collect data for program assessment. As faculty continue shifting from teaching-efficient to learning-efficient models [24], there is speculation that faculty use of ET may increase [25], but no studies to date have assessed the present and future ET needs of CCC faculty. Therefore, what was needed was a study designed to survey CCC faculty to determine their present ET hardware and software use and their anticipated increase or decrease in ET hardware and software use five years into the future. Using quantitative survey methodology, the present study was specifically designed to fill this gap in the literature. The hypotheses for this study were:

- $\mathrm{H}_{0} 1$ : There is no statistically significant difference between the present and future ET hardware needs of the sample of CCC faculty.

- $\mathrm{H}_{\mathrm{A}} 1$ : There is a statistically significant difference between the present and future ET hardware needs of the sample of CCC faculty.

- $\mathrm{H}_{0}$ 2: There is no statistically significant difference between the present and future ET software needs of the sample of CCC faculty.

- $\mathrm{H}_{\mathrm{A}} 2$ : There is a statistically significant difference between the present and future ET software needs of the sample of CCC faculty.

Further, to gauge the frequency faculty were sought to provide stakeholder input regarding ET, participants were asked, "When was the last time you were asked for meaningful input regarding Educational Technology by an administrator, IT, or another influencer?"

\section{METHODOLOGY}

\subsection{Participants}

Participants for this study were 655 active CCC faculty with email addresses available through college websites and webpages during the months of February and March 2016. Completing the survey was voluntary. 


\subsection{Procedures}

Approval was received from the Institutional Review Board of Argosy University prior to beginning the study. Permissions were received from the California Community College Chancellor's Office to use faculty email addresses available through college websites. Each participant completed an informed consent prior to access to the survey questions. This research study complied with the ethical guidelines related to anonymity, privacy, and confidentiality, in accordance with the guidelines set forth in the Code of Federal Regulations and the Belmont Report [26].

Data were collected online through SurveyMonkey® (SurveyMonkey.com) over a 10-day period. Invitations were emailed, reminder emails were sent on day five, and the survey closed on day 10. Participants could participate from any computer or location of their preference. Participants were asked to select one class that they commonly teach and to respond to survey items in the context of teaching that particular class. A progress bar provided a visual to the participant showing the percentage of the survey completed. A "Thank You" page signaled completion of the survey.

Data management of survey results required password-protected access to the SurveyMonkey ${ }^{\circledR}$ website. Only the researcher had the personal password to download the data. Survey data were treated confidentially and participation was anonymous, as no individuating information was collected and no identifying campus information was included in the reported findings. Of the 890 responses, 235 were incomplete and therefore removed from the data set. The remaining 655 complete data records were coded, checked for errors, and then exported to SPSS statistical software (Version 23.0; Armonk, NY: IBM Corp.) for analysis.

\subsection{Measures}

The survey included 37 items related to HW and SW usage, stakeholder input, and demographics. Thirty questions asked faculty about their present use of ET hardware and software and their anticipated use five years into the future. The response interface was a 5 -point Likert type format $(1=$ Never, $2=$ Once or Twice per Term, $3=$ Several Times per Term, $4=$ Half of Class Sessions or More, $5=$ Most Every Class Session). The item regarding stakeholder input frequency was in a single-response multiple-choice format (Never, Within 12 months, Other). The six demographic questions were in multiple-choice format.

The survey items were adapted from previous research completed by Guidry and BrckaLorenz [12], Ithaca College [15, 16], San Diego State University [17], the Wisconsin University System [18], San Jose State University [19], University of California at Santa Barbara [20], and California State University Northridge [27]. A pilot test survey was conducted prior to formal data collection to determine the face validity, content validity, and construct validity of the survey, in addition to the survey format and readability. Minor survey instrument revisions were then made based on suggestions from pilot study participants.

\section{DESIGN AND ANALYSIS}

\subsection{Study Design}

This study employed a cross-sectional survey design, in that participants were each measured once. This study could also be categorized as an observational design in that there was no random assignment to groups and no experimentally controlled treatment [28,29].

\subsection{Analysis}

The analysis plan included operationalization of variables, statistical analysis, and criteria for interpretation. Descriptive statistics for each analysis are expressed as mean $(M)$ and standard deviation $(S D)$ values or as frequencies and percentages in the text. Table 1 displays the operationalization of ET hardware and ET software variables.

Table 1: Educational technology study variables

\begin{tabular}{cc}
\hline Hardware & Software \\
\hline Response tools & SLO assessment \\
Computers & Multiuser interactive \\
Capture devices & Social networking \\
Projection devices & Multimedia \\
Smart boards & Specialty software \\
Smartphones & Class assignment evaluation \\
& Course web page \\
& Email \\
& Office suites \\
\hline
\end{tabular}

The present and future use of ET hardware and software responses were coded on a five-point scale for statistical analysis: 1 = Never, 2 = Once or Twice per Term, 3 = Several Times per Term, $4=$ Half of Class Sessions or More, $5=$ Most Every Class Session. Responses of "Never heard of it" were treated as missing values. Differences between current 
and future ET hardware (H1) and between current and future ET software (H2) use were evaluated using paired $t$-tests. The assumption of independence was fostered because one person's score does not affect another's scores. Differences were considered statistically significant at the $p<.05$ threshold. Effect sizes were calculated as Cohen's D [30], expressed as the difference between means in units of standard deviation $(S D)$, and categorized as small $(d=.20$ or smaller), medium $(d=.50)$, or large $(d=.80$ or larger) effects. Descriptive statistics are expressed as $M$ and $S D$, or as frequencies and percentages, as appropriate, in tables and text.

\section{RESULTS}

\subsection{Participant Demographics}

Percentages of respondents within the demographic areas of this study are shown in Table 2 and Table 3. Approximately three-quarters of the courses faculty selected as a reference for framing their responses were reported as taught "on-ground" (Table 2).

Table 2: Delivery mode as a percentage of the sample $(N=655)$

\begin{tabular}{lcc}
\hline \multicolumn{1}{c}{ Demographic } & Survey \% & National \% \\
\hline Course delivery mode & 100 & --- \\
Hybrid & 11.9 & --- \\
On-ground & 74.8 & ---- \\
Online & 9.9 & ---- \\
Other & 3.4 & ---- \\
\hline
\end{tabular}

In Table 3, where possible, results are compared to national levels using data published by the National Center for Education Statistics (NCES). Respondents included both full-time (42.1\%) and other than full-time (57.9\%) faculty. Participants reporting holding a master's or a terminal degree $(87.9 \%)$ were somewhat higher than NCES results. Professors (28.7\%), associate professors (7.5\%), assistant professors (8.7\%), and non-professors (55.1\%) comprised the sample and did not closely mirror NCES reports. Most participants were non-Hispanic Caucasian (70.2\%) reflecting similar NCES results. More females responded (54\%) than males (44\%), almost the reverse of NCES demographics.

Table 3: Response characteristics as a percentage of the sample $(N=655)$

\begin{tabular}{lcc}
\hline \multicolumn{1}{c}{ Demographic } & Survey $\%$ & National \% \\
\hline Employment status Total & 100 & $100^{31}$ \\
Yes, full-time & 42.1 & 51.3 \\
Not full-time & 57.4 & 48.7 \\
Other than above & 0.5 & --- \\
Highest Degree Total & 100 & $100^{32}$ \\
Doctorate/Terminal/MFA & 27.3 & 15.8 \\
Master's & 60.6 & 57.7 \\
Bachelor's & 6.9 & 16.3 \\
Other than above & 5.2 & 10.2 \\
Academic Rank Total & 100 & $100^{33}$ \\
Professors & 28.7 & 22.9 \\
Associate professors & 7.5 & 19.6 \\
Assistant professors & 8.7 & 21.0 \\
Other than above & 55.1 & 36.5 \\
Race/Ethnicity Total & 100 & $100^{33}$ \\
Caucasian (non-Hispanic) & 70.2 & 72.7 \\
Hispanic/Latino & 7.5 & 4.2 \\
Asian/Pacific Islanders & 6.5 & 9.1 \\
African-American (non-His & 5.0 & 5.5 \\
Native American or Aleut & 1.2 & 0.4 \\
Other than above & 9.6 & 8.1 \\
Gender Total & 100 & $100^{34}$ \\
Female & 54.9 & 48.7 \\
Male & 44.0 & 51.3 \\
Other than above & 1.1 & --- \\
\hline Note: Category totals may not sum to & $100 \%$ due to rounding.
\end{tabular}

\subsection{Present and Future ET Hardware Use}

RQ1 sought to identify similarities and differences between current and future ET hardware use by CCC faculty. Aggregate scores for ET hardware were calculated per participant by averaging across all ET hardware categories. 
Hypothesis testing was conducted on the current use and future use aggregate scores, then for each individual ET hardware item. As an aggregate, respondents anticipated a significant increase in ET hardware use over the next five years. On a 1 to 5 scale from "Never" to "Most Every Class Session," current ET hardware averaged $2.7(S D=0.7)$, between "Once or Twice per Term" and "Several Times per Term" (Table 4). In five years, ET hardware is anticipated to increase to $3.3(S D=0.8)$, indicating use will be between "Several Times per Term" and "Half of Class Sessions or More." The difference was statistically significant $(t[653]=23.8, p<.001)$. The effect size was large $(d=0.93)$ by the criteria of Cohen [30]. This finding rejected null hypothesis 1.

Table 4: Current and future ET hardware use

\begin{tabular}{lcccccrcc}
\hline & \multicolumn{7}{c}{ Current } & \multicolumn{2}{c}{ Future } & & & \\
Hardware & $M$ & $S D$ & $M$ & $S D$ & $d f$ & \multicolumn{1}{c}{$t$} & $p$-value & Cohen's $d$ \\
\hline Aggregate hardware & 2.7 & 0.7 & 3.3 & 0.8 & 653 & 23.8 & $<.001$ & .93 \\
Response tools & 1.5 & 1.1 & 2.3 & 1.5 & 577 & 16.5 & $<.001$ & .68 \\
Computers & 4.6 & 0.9 & 4.7 & 0.8 & 647 & 3.1 & .002 & .12 \\
Capture devices & 2.2 & 1.4 & 3.0 & 1.5 & 643 & 16.5 & $<.001$ & .65 \\
Projection devices & 4.1 & 1.4 & 4.1 & 1.4 & 644 & 1.1 & .270 & .04 \\
Smart boards & 1.7 & 1.4 & 2.8 & 1.6 & 627 & 17.7 & $<.001$ & .71 \\
Smartphones & 2.1 & 1.4 & 2.7 & 1.5 & 625 & 13.6 & $<.001$ & .54 \\
\hline
\end{tabular}

For specific ET hardware, statistically significant differences between current and future use of hardware were apparent for four of the six hardware elements: response tools, capture devices, smart boards, and smartphones, with medium to large effect sizes (Table 4). The computer and projection devices each had high current and future use. Differences between current and future use of computers were statistically significant, but the effect size was small $(d=$ .12). Differences between current and future use of projection devices were not statistically significant.

Table 5 shows current and future hardware use in percentages. Response tools provide an avenue for faculty to promote active learning, ensure active engagement of remote access students, and collect data to assess students' understanding of content under discussion [35]. Currently $74 \%$ of faculty do not use response tools but only $45 \%$ do not plan on using response tools in the future. The largest increases are anticipated to be in the "Several Times per Term" $(+324 \%)$ and "Half of Sessions or More" $(+348 \%)$ while use in "Most Every Class Session" in the next five years is expected to double $(+131 \%)$.

Capture devices include cameras, video, and audio recorders, which provide instructors with opportunities to develop course content and record instruction for repeated viewing by students and thereby foster asynchronous learning. Faculty anticipate more than a $50 \%$ increase in the use of capture devices "Several Times per Term" (57\%), "Half of Class Sessions or More" (80\%), or "Most Every Class Session" (81\%).

Smart boards, also commonly referred to as digital whiteboards, connect through computers and provide interactive screens to enhance the learning environment. These devices also serve to capture material displayed or created during class for later reference. Roughly three quarters of faculty do not currently use smart boards, but in the future, six in ten faculty anticipate using smart boards at some time during the term. Faculty speculated that their use of smart boards in "Most Every Class Session" will double, from $12 \%$ currently to $24 \%$ in 5 years.

Smartphones connect students and faculty to the world through the use of social networking applications and also offer a variety of coursework support tools. While half of participants $(51 \%)$ reported that they presently do not use smartphones, this will decline to $35 \%$ in 5 years, with the largest increase (74\%) in using smartphones in "Most Every Class Session."

Table 5: ET hardware usage (percent of participants)

\begin{tabular}{|c|c|c|c|c|c|c|c|}
\hline & Time & Never & $\begin{array}{l}\text { Once or } \\
\text { Twice per } \\
\text { Term }\end{array}$ & $\begin{array}{c}\text { Several } \\
\text { Times per } \\
\text { Term } \\
\end{array}$ & $\begin{array}{c}\text { Half of Class } \\
\text { Sessions or } \\
\text { More }\end{array}$ & $\begin{array}{c}\text { Most Every } \\
\text { Class } \\
\text { Session } \\
\end{array}$ & $\begin{array}{c}\text { Never } \\
\text { Heard } \\
\text { of it }\end{array}$ \\
\hline \multirow[t]{3}{*}{ Response tools } & Now & 74 & 5 & 4 & 2 & 6 & 9 \\
\hline & In 5 years & 45 & 8 & 18 & 9 & 13 & 7 \\
\hline & Change/Time\% & -39 & 59 & 324 & 348 & 131 & -21 \\
\hline \multirow[t]{3}{*}{ Computers } & Now & 3 & 3 & 7 & 7 & 80 & 0 \\
\hline & In 5 years & 2 & 2 & 6 & 8 & 82 & 1 \\
\hline & Change/Time\% & -27 & -39 & -12 & 11 & 2 & 33 \\
\hline \multirow[t]{3}{*}{ Capture devices } & Now & 45 & 19 & 16 & 7 & 12 & 0 \\
\hline & In 5 years & 23 & 16 & 25 & 13 & 23 & 1 \\
\hline & Change/Time $\%$ & -49 & -14 & 57 & 80 & 81 & 33 \\
\hline \multirow[t]{2}{*}{ Projection devices } & Now & 13 & 4 & 9 & 10 & 63 & 0 \\
\hline & In 5 years & 11 & 4 & 10 & 10 & 63 & 1 \\
\hline
\end{tabular}


Smart boards

Smartphones

\begin{tabular}{lrrrrrr} 
Change/Time\% & -11 & 0 & 8 & 3 & 0 & 67 \\
\hline Now & 72 & 7 & 4 & 3 & 12 & 2 \\
In 5 years & 37 & 11 & 14 & 12 & 24 & 2 \\
Change/Time\% & -49 & 62 & 242 & 347 & 100 & -8 \\
\hline Now & 51 & 15 & 17 & 5 & 12 & 0 \\
In 5 years & 35 & 14 & 23 & 9 & 20 & 0 \\
Change/Time\% & -32 & -9 & 31 & 61 & 74 & 0 \\
\hline
\end{tabular}

In summary, CCC faculty demand for ET hardware will increase in the next five years, with the largest increases in the use of response tools, capture devices, smart boards, and smartphones. Little change is expected in the use of computers or projection devices.

\subsection{Present and Future ET Software Use}

RQ2 sought to identify similarities and differences between current and future ET software use by CCC faculty. Aggregate scores for ET software were calculated per participant by averaging across all ET software categories. Hypothesis testing was conducted on the current use and future use aggregate scores, then for each individual ET software item. As an aggregate, ET software use will increase in the next five years. On a 1 to 5 scale from "Never" to "Most Every Class Session," current ET software averaged 3.0 (SD =0.8), corresponding to "Several Times per Term" (Table 6). In five years, ET software is anticipated to increase to $3.5(S D=0.9)$, between "Several Times per Term" and "Half of Class Sessions or More." This difference was statistically significant $(t[653]=20.6, p<.001)$. The effect size was large $(d=0.8)$. This finding rejected null hypothesis 2 .

For specific ET software, statistically significant increases were apparent for eight of the nine software elements, with medium to large effect sizes for student learning outcome (SLO) assessment, multiuser interactives, and social networking (Table 6). Multimedia, specialty software, class assignment evaluation, course web page, and email also indicated statistically significant differences between current and future use, with effect sizes range from small to medium. The expected change in the use of Office suites was not statistically significant because current use is high and that high use is expected to continue.

Table 6: Current and future ET software use

\begin{tabular}{lcccccccc}
\hline & \multicolumn{1}{c}{ Current } & \multicolumn{2}{c}{ Future } & \multicolumn{2}{c}{} \\
Software & $M$ & $S D$ & $M$ & $S D$ & $d f$ & $t$ & $p$-value & Cohen's $d$ \\
\hline Aggregate software & 3.0 & 0.8 & 3.5 & 0.9 & 653 & 20.6 & $<.001$ & .81 \\
SLO assessment & 1.8 & 1.2 & 2.5 & 1.4 & 561 & 13.9 & $<.001$ & .59 \\
Multiuser interactive & 2.4 & 1.5 & 3.2 & 1.4 & 628 & 14.8 & $<.001$ & .59 \\
Social networking & 2.2 & 1.5 & 2.9 & 1.5 & 643 & 16.6 & $<.001$ & .65 \\
Multimedia & 3.5 & 1.2 & 3.9 & 1.2 & 643 & 12.1 & $<.001$ & .48 \\
Specialty software & 2.1 & 1.5 & 2.5 & 1.6 & 588 & 8.9 & $<.001$ & .37 \\
Class assignment & 3.5 & 1.7 & 3.9 & 1.4 & 610 & 9.5 & $<.001$ & .38 \\
evaluation & 3.5 & 1.7 & 3.9 & 1.5 & 542 & 8.5 & $<.001$ & .36 \\
Course web page & 4.2 & 1.0 & 4.3 & 1.0 & 618 & 2.3 & .019 & .09 \\
Email & 4.2 & 1.3 & 4.2 & 1.2 & 641 & 1.5 & .126 & .06 \\
Office suites & & & & & & & & \\
\hline
\end{tabular}

Table 7 shows current and future software use in percentages. SLO assessment tools are designed for the collection of data for overall class or program success. Examples of SLO tools include Cal-PASS Plus Program and the CCC Student Success Scorecard. Presently, half of participants "Never" use SLO assessment, but in 5 years, this will decline to less than one-third of faculty. Large increases in the use of SLO assessment "Several Times per Term" (144\%), Half of Class Sessions or More "(201\%), or "Most Every Class Session” (89\%) are expected in 5 years.

Screen sharing and Google.docs are common examples of multiuser interactive tools that are conducive to creating collaborative environments for teamwork and project development. Presently, approximately four in ten participants "Never" use multiuser interactive software, but this is expected to decline to $16 \%$ in 5 years. Multiuser interactive usage for "Most Every Class Session" is expected to increase by $76 \%$.

Social networks, such as Facebook, MySpace, and LinkedIn provide environments for sharing similar interests, activities, new information, photos, videos, and blogs $[18,36]$. Large increases (Table 6) are expected in the use of social networking tools for "Most Every Class Session" (62\%) for "Half of Class Sessions or More" (132\%) in five years (Table 7).

Video, YouTube, and podcasts provide multimedia environments for sharing ideas and content, and also provide learners the opportunity to access the content outside the classroom with the ability to repeat content as needed. Multimedia usage is expected to significantly increase in five years (Table 6). Less than one in ten of participating CCC 
faculty "Never" use multimedia for their classes now, but in five years, faculty anticipate increasing their use of these types of media by $49 \%$ in "Most Every Class Session" (Table 7).

Specialty software is most frequently used in music, writing, computational, and design programs. In five years, the use of specialty software for "Most Every Class Session "is anticipated to increase by $42 \%$. It is important to note that four in ten of respondents indicated they anticipate "Never" using specialty software in 5 years.

Gradebooks, TurnItIn, Canvas, and Blackboard represent software tools used by faculty for class assignment evaluation. Currently, one quarter of participants "Never" use class assignment tools, but this may decline to one in ten in 5 years. Further, infrequent use ("Once or Twice per Term") may decline while more frequent use ("Several Times per Term," "Half of Class Sessions or More", or "Most Every Class Session") is anticipated to increase in 5 years (Table 7).

Class webpages generally receive high student ratings [36] and provide a versatile environment for faculty to offer students $24 / 7$ access to course materials. One quarter of faculty "Never" use class web pages, but this may decline to one in ten in 5 years. Further, the infrequent use of class webpage software ("Once or Twice per Term") may decline, while the more frequent use ("Several Times per Term," "Half of Class Sessions or More", or "Most Every Class Session") is anticipated to increase in 5 years. Less than one in ten participants indicated that they currently "Never" use office suites and more than six in ten indicated that they use this software "Most Every Class Session" (Table 7).

The use of email and office suite were the highest among ET software categories (Table 6) and are expected to remain equally high over the next five years (Table 7).

Table 7. ET software usage (percent of participants)

\begin{tabular}{|c|c|c|c|c|c|c|c|}
\hline & Time & Never & $\begin{array}{l}\text { Once or } \\
\text { Twice } \\
\text { per Term }\end{array}$ & $\begin{array}{c}\text { Several } \\
\text { Times } \\
\text { per Term }\end{array}$ & $\begin{array}{c}\text { Half of Class } \\
\text { Sessions or } \\
\text { More }\end{array}$ & $\begin{array}{c}\text { Most Every } \\
\text { Class } \\
\text { Session }\end{array}$ & $\begin{array}{c}\text { Never } \\
\text { Heard of } \\
\text { it }\end{array}$ \\
\hline \multirow[t]{3}{*}{ SLO assessment } & Now & 56 & 17 & 5 & 3 & 7 & 11 \\
\hline & In 5 years & 30 & 23 & 13 & 10 & 14 & 10 \\
\hline & Change/Time $\%$ & -46 & 32 & 144 & 201 & 89 & -1 \\
\hline \multirow[t]{3}{*}{ Multiuser interactives } & Now & 39 & 18 & 17 & 10 & 14 & 2 \\
\hline & In 5 years & 16 & 18 & 24 & 16 & 25 & 1 \\
\hline & Change/Time $\%$ & -59 & -1 & 43 & 59 & 76 & -50 \\
\hline \multirow[t]{3}{*}{ Social networking } & Now & 50 & 16 & 13 & 7 & 14 & 0 \\
\hline & In 5 years & 25 & 18 & 19 & 16 & 22 & 0 \\
\hline & Change/Time\% & -51 & 15 & 46 & 132 & 62 & -33 \\
\hline \multirow[t]{3}{*}{ Multimedia } & Now & 8 & 13 & 30 & 20 & 29 & 0 \\
\hline & In 5 years & 5 & 7 & 26 & 19 & 43 & 0 \\
\hline & Change/Time $\%$ & -35 & -47 & -12 & -5 & 49 & -67 \\
\hline \multirow[t]{3}{*}{ Specialty SW } & Now & 58 & 8 & 8 & 6 & 15 & 6 \\
\hline & In 5 years & 40 & 12 & 12 & 8 & 21 & 8 \\
\hline & Change/Time $\%$ & -30 & 47 & 42 & 32 & 42 & 43 \\
\hline \multirow[t]{3}{*}{ Class assignment } & Now & 24 & 7 & 10 & 11 & 45 & 2 \\
\hline & In 5 years & 11 & 5 & 17 & 12 & 53 & 2 \\
\hline & Change/Time $\%$ & -53 & -28 & 58 & 3 & 18 & 9 \\
\hline \multirow[t]{3}{*}{ Class web pages } & Now & 26 & 7 & 10 & 6 & 50 & 1 \\
\hline & In 5 years & 13 & 8 & 13 & 11 & 54 & 2 \\
\hline & Change/Time $\%$ & -51 & 8 & 36 & 79 & 8 & 34 \\
\hline \multirow[t]{3}{*}{ Email } & Now & 2 & 4 & 21 & 18 & 54 & 0 \\
\hline & In 5 years & 3 & 3 & 20 & 15 & 59 & 0 \\
\hline & Change/Time $\%$ & 18 & -33 & -3 & -18 & 9 & -1 \\
\hline \multirow[t]{3}{*}{ Office Suites } & Now & 7 & 6 & 12 & 11 & 64 & 1 \\
\hline & In 5 years & 6 & 5 & 14 & 11 & 64 & 1 \\
\hline & Change/Time\% & -22 & -9 & 15 & 4 & 0 & 0 \\
\hline
\end{tabular}

In summary, large increases are expected in ET software use in the categories of SLO assessment, multiuser interactive, and social networking software over the next five years. Smaller increases are expected in the use of multimedia, specialty software, and class assignment evaluation software. Use of office suites and email are anticipated to remain stable.

\subsection{Asked About ET by an Influencer}

Table 8 shows that $42 \%$ of participating CCC faculty had never ben asked for input regarding ET by an influencer, while $51 \%$ had been asked during the last year, and $7 \%$ had been asked over a different time period. 
Table 8: Last time asked by influencer for input regarding ET (percent of participants)

\begin{tabular}{cccc} 
& Never & Within 12 Months & Other Time Period \\
\hline Asked? & 42 & 51 & 7 \\
\hline
\end{tabular}

\section{DISCUSSION}

Present study results of anticipated increases in ET use among CCC faculty are consistent with university-level surveys $[12,15,16,18]$. This study extends previous findings to include the California community college system and includes a five-year window into the future. The ET revolution may be best exemplified by the observation that more than $95 \%$ of the participants in the present study use computers and $85 \%$ use projection devices. These findings were consistent with the San José State University survey [19] and the 2011 and 2013 surveys at Ithaca College [15,16], which found that faculty reported computers and projection devices among the most important classroom technologies for faceto-face teaching.

CCC faculty anticipated increasing their use of ET hardware over the next five years. This increase is not surprising, given that Brown [37] found that student ownership of digital devices used for academics increased by $20 \%$ between 2013 and 2014. The greatest increases in hardware demand are expected for response tools, smart boards, capture devices, and smartphones. These findings were consistent with the San José State University [19] survey, which found that smart boards, document cameras, and smartphones were among the most common technology tools used in the classroom by faculty. Present findings replicate the results of the San José State University [19] survey and extend these findings to indicate that the demand for these ET hardware items will continue to grow. Not only will the use of ET hardware increase, but also the percentage of CCC faculty not using ET hardware will decrease. For these reasons, the CCCs should anticipate an increase in faculty use of ET hardware.

Dramatic increases in the use of ET software should be anticipated in the use of SLO assessment, social networking, and multiuser interactives in the next five years. Present results also show that CCC faculty anticipate significant increases in the use of multimedia (e.g., video, YouTube, and podcasts), specialty software, course web pages, and course assignment evaluation software. More than $99 \%$ of community colleges have learning management systems in place to support student success and have an average of $85 \%$ of faculty using the technology [38]. Twenty-four hour access to course material is important to students [39] and can have a positive effect on VOI [1]. Similar to other university surveys, office suite software and email are already in high use [15,16,17,18,19,20] and little change is anticipated $[15,16,20]$. The finding that $42 \%$ of CC faculty had ever been asked for their view on ET demonstrates that faculty are an under-utilized resource in making ET decisions within the CCC.

\section{IMPLICATIONS}

The present study provides empirical evidence that CCC administrative decision makers should anticipate increased demand for ET hardware and ET software over the next five years, and should budget accordingly. For decision makers, this information can be critical towards determining where the expenditure of scarce resources can be best allocated towards improving ROI and VOI. This is particularly important in the present era of constrained resources. Also, the present study demonstrates that simple survey methodology can be invaluable in the forward planning of large businesses, like the CCC system. Lastly, the observation that four in ten CCC faculty had never been consulted regarding ET implies that the faculty are an under-utilized resource in the context of determining ET needs. Regular periodic surveys of CCC faculty are warranted to ensure that the CCC decision-makers can identify changes in ET trends and appropriately adjust strategies towards continually improving ROI, VOI, and competitiveness.

\section{LIMITATIONS}

While the large sample size $(N=655)$ was a strength of the study, the participant pool was limited by the availability of current CCC faculty email addresses on college website directories. Faculty who were less comfortable with ET may have been less likely to participate. The majority of respondents were from the Southern California region, but CCC curriculum is similar throughout the state, which ameliorated this potential source of bias. This study was specifically designed to assist the CCCs in making future decisions regarding the allocation of scarce resources, so it might be inappropriate to generalize the present findings beyond the CCCs. Additionally, the results should be generalized with caution, as the study measures were all self-report, with no objective measures of ET use (e.g., classroom observations).

\section{AREAS OF FUTURE RESEARCH}

Periodic replication of the present study with larger and more diverse samples would be beneficial, as would the inclusion of other stakeholders (e.g., students, prospective students, staff, and administrators), objective measures, and third party reports to bring convergent validity to self-report data. Including student input is of particular importance because students are the customers in the business of higher education. For example, course assignment evaluation and 24-hour access to course materials can foster learning [38, 40, 41] and are rated as "important" by students [39], but half 
of participating CCC faculty do not currently utilize student learning outcome software and one-quarter do not use classroom assignment software or class webpages.

In a larger context, longitudinal research of ET use by campus faculty could be aggregated into a larger report that would be beneficial to policymakers towards determining state budgetary recommendations and for state leaders seeking opportunities to leverage economies of scale.

Some faculty perceived the use of ET as "not useful," which implies that there may be benefit in delving more deeply into specific areas of ad hoc ET use by faculty, such as curriculum development, program assessment, and assessment of student progress within courses. It is possible that some faculty do not fully appreciate the value in using ET, so research to determine the effects of ET training on effective classroom use of ET is warranted towards preventing loss of ROI and VOI.

In the present study, more than four in ten faculty reported having never been asked regarding their ET use. It is therefore important that future research is conducted to determine the effect of faculty input on ET decision making, and ways to maximize the impact of faculty input on ET decisions. Lastly, the present study did not differentiate between different academic areas and ET usage. For example, contrasting differences in ET needs between career and technical education and traditional education may prove insightful towards assisting CCC decision makers in maximizing the ROI and VOI benefits of ET expenditures while minimizing the inappropriate allocation of scarce ET resources.

\section{CONCLUSIONS}

ET has become a centerpiece in the competitive arena of higher education as an integral component of fiscal sustainability strategies because "the most successful institutions will be those that can respond quickest and offer a highquality education" [42, p. 1]. Mott and Granata, [43] suggested that resource allocation should consider maximizing the use of instructional materials and effectively managing ET resources. While ET is an expensive investment, ET is needed to maximize the productivity, efficiency, and competitiveness of the CCC system. Results of this study support the hypothesis that the use of ET hardware and ET software will increase over the next five years, so CCC decision makers must be prepared to make appropriate allocations to fill these needs. Present findings also indicate that four in ten CCC faculty have never been asked regarding the ET use, which suggests that periodic surveys of CCC faculty will be needed to ensure that the CCC system can continually maximize ROI, VOI, and competitiveness through wise decision making in the allocation of scarce ET resources.

\section{REFERENCES}

[1] Christensen, C. M., Horn, M. B., Caldera, L., \& Soares, L. (2011). Disrupting college: How disruptive innovation can deliver quality and affordability to postsecondary education. Center for American Progress and Innosight Institute. Retrieved from https://www.americanprogress.org/issues/labor/report/2011/02/08/9034/disruptingcollege/

[2] Immerwahr, J., Johnson, J., \& Gasbarra, P. (2008). The iron triangle: College presidents talk about costs, access, and quality. National Center Report\# 08-2. National Center for Public Policy and Higher Education. Retrieved from http://eric.ed.gov/?id=ED503203

[3] Murray, M. C., \& Pérez, J. (2015). Informing and performing: A study comparing adaptive learning to traditional learning. DigitalCommons@ Kennesaw State University. Retrieved from http://www.inform.nu/Articles/Vol18/ISJv18p111-125Murray1572.pdf

[4] Kirshstein, R., \& Wellman, J. (2012). Technology and the broken higher education cost model: Insights from the Delta Cost Project. Educause Review, 47(5), 12-22.

[5] Shulock, N., \& Offenstein, J. (2012). Institute for Higher Education Leadership \& Policy. Career Opportunities: Career Technical Education and the College Completion Agenda, Part I: Structure and Funding of Career Technical Education in the California Community Colleges. Sacramento, CA: California State University. Retrieved from http://eric.ed.gov/?id=ED534073

[6] Pathak, V. \& Pathak, K. (2010), Reconfiguring the higher education value chain. Management in Education, 24(4), 166-171.

[7] Tomašević, I., Stojanović, D., Simeunović, B., Radović, M., \& Andrić-Gušavac, B. (2015, August). Proceedings from 14th Toulon-Verona Conference: Organizational Excellence in Services. Creating Value in Higher Education Institutions, 1179-1188. ISBN: 978 88904327-1-2

[8] Bowen, W. G. (2012). The "cost disease" in higher education: Is technology the answer. The Tanner Lectures, Stanford University. Retrieved from http://www.ithaka.org/sites/default/files/files/ITHAKATheCostDiseaseinHigherEducation.pdf

[9] Hutaibat, K. A. (2011). Value chain for strategic management accounting in higher education. International Journal of Business and Management, 6(11), 206. doi:10.5539/ijbm.v6n11p206 
[10] Zemsky, R. (2013). Checklist for change: Making American higher education a sustainable enterprise. New Brunswick, NJ: Rutgers University Press. [1] Lapovsky, L. (2013). The Higher Education Business Model. Retrieved from http://agb.org/sites/default/files/legacy/2014_nct_tiaa_cref.pdf

[11] Mirriahi, N., \& Alonzo, D. (2015). Shedding light on students' technology preferences: Implications for academic development. Journal of University Teaching and Learning Practice, 12(1), 6.

[12] Guidry, K. R., \& BrckaLorenz, A. (2010). A comparison of student and faculty academic technology use across disciplines. $\quad$ Educause Quarterly, 33(3), $\quad$ 1-12. Retrieved from http://www.emich.edu/strategicplan/documents/supporting_materials/trends_in_higher_education_and_the_labor_ market.pdf

[13] Freeman, R. E., \& Reed, D. L. (1983). Stockholders and stakeholders: A new perspective on corporate governance. California Management Review, 25(3), 88. Retrieved from http://originsearch.proquest.com/docview/216132147?accountid=34899

[14] Freeman, R. E. (1994). The politics of stakeholder theory: Some future directions. Business ethics quarterly, 4(4), 409-421.

[15] Taves, M., \& Dispensa, M. (2013). Ithaca College 2013 Faculty survey on instructional technology final report. Information $\quad$ Technology $\quad$ Services. $\quad$ Retrieved from http://www.ithaca.edu/its/services/iss/docs/facsurvey/2013FacSurveyFinal.pdf

[16] Taves, M., Dispensa, M., \& Borch, C. (2011). 2011 Faculty survey on instructional technology final report. Ithaca College. Retrieved from http://www.ithaca.edu/its/services/iss/docs/facsurvey/2013FacSurveyFinal.pdf

[17] Frazee, J. P. (2014). Report on results from instructional technology services faculty support survey - 2014. San Diego, CA: San Diego State University. Retrieved from http://its.sdsu.edu/docs/2014-its-survey-report.pdf

[18] Hartman, A., Barnet, B., Pfeifer-Luckett, R., Mann, P., \& Wong, L. (2014). Faculty \& staff survey on online teaching, learning \& support report - 2014. Learn@UW Executive Committee. Retrieved from https://www.wisconsin.edu/systemwide-it/download/it-projects/fac-survey/Faculty Survey Final Report - 2014.pdf

[19] San José State University Annual Report. (2014). Annual report: 2014 SJSU faculty survey summary on instructional technology. Information Technology Services and Academic Technology Departments. http://www.sjsu.edu/at/ec/Survey/SJSU_2014_Faculty_Survey_Summary_Instructional_Technology.pdf

[20] University of California. (2002). Office of Information Technology at Santa Barbara: Faculty questionnaire on the use of information technology in teaching. Retrieved from http://www.oit.ucsb.edu/committees/ATWG/2002_faculty_survey.pdf

[21] California Community College Chancellor's Office. (2015). Management information systems data mart: Fall 2015 employees. http://datamart.cccco.edu/Faculty-Staff/Staff_Demo.aspx

[22] Harris, B. (2016). California community college chancellor's office: Long range master plan. Retrieved from http://californiacommunitycolleges.cccco.edu/Portals/0/Reports/MasterPlan_2016_ADA_Final.pdf

[23] Brown, E. G. (2016, January). Governor's 2016-2017 Budget Summary. California Legislature Regular Session 2015-16. Retrieved from http://www.ebudget.ca.gov/FullBudgetSummary.pdf

[24] Jones, N. A. (2006). From "sage on the stage" to "guide on the side": The challenge for educators today. ABAC Journal 26(1), 1-18. Retrieved from http://www.journal.au.edu/abac_journal/2006/jan06/vol26no1_article01.pdf

[25] Harker, P. (2014). Commentary-making sense of higher education's future: An economics and operations perspective. Service Science 6(4), 207-216. http://dx.doi.org/10.1287/serv.2014.0079

[26] Argosy University. (2014). Institutional Review Board Handbook - September 2014. Retrieved from https://ucmrp.edmc.edu/idc/groups/webcontent/@edmc_aug/documents/webcontent/edmc-03428020.pdf

[27] Goldstein \& Associates (2011). California State University Northridge: 2011 Information technology 2011 survey analysis. Retrieved from http://www.csun.edu/sites/default/files/techsurvey11_analysis.pdf

[28] Campbell, D. T., \& Stanley, J. C. (1963). Experimental and quasi-experimental designs for research on teaching. American Educational Research Association.

[29] Tabachnick, B. G., \& Fidell, L. S. (2007). Experimental designs using ANOVA. Thomson/Brooks/Cole

[30] Cohen, J. (1992). A power primer. Psychological Bulletin, 112(1), 155. doi:10.1037/0033-2909.112.1.155

[31] National Center for Education Statistics. (2014a). The digest of educational statistics. 2013 All faulty, all colleges., employment. Retrieved from http://nces.ed.gov/programs/digest/d14/tables/dt14_315.10.asp

[32] National Center for Education Statistics. (2014b). The digest of educational statistics. 2003 All faculty in 2 year colleges, degree. Retrieved from http://nces.ed.gov/programs/digest/d14/tables/dt14_315.50.asp

[33] National Center for Education Statistics. (2014c). The digest of educational statistics. 2013 All full time faculty, all colleges, rank, ethnicity. Retrieved from http://nces.ed.gov/programs/digest/d14/tables/dt14_315.20.asp

[34] National Center for Education Statistics. (2014d). The digest of educational statistics. 2013 All full time faculty, all colleges, gender. Retrieved from http://nces.ed.gov/programs/digest/d14/tables/dt14_314.20.asp

[35] Kukulska-Hulme, A. \& Traxler, J. (Eds.). (2007). Mobile learning. A handbook for educators and trainers. The International Review of Research in Open and Distributed Learning, 8(2). Retrieved from http://www.irrodl.org/index.php/irrodl/rt/printerFriendly/356/879

[36] Ferriter, W. M., \& Ramsden, J. T. (2012). Communicating \& connecting with social media. Solution Tree Press. 
[37] Brown, M. (2015, July/August). Six trajectories for digital technology in higher education. EDUCAUSE Review 50(4). Retrieved from http://er.educause.edu/articles/2015/6/six-trajectories-for-digital-technology-in-highereducation

[38] Dahlstrom, E., \& Bichsel, J. (2014). ECAR study of undergraduate students and information technology. [Research report]. Louisville, CO. Retrieved from http://www.educause.edu/ecar

[39] Harvard University. (2008). Instructional technology survey. Cambridge, MA: Department of Romance Languages and Literatures. Retrieved from http://blogs.law.harvard.edu/digitalnatives/files/2008/03/instructionaltechnologysurvey.pdf

[40] Elzarka, S. (2012). Technology use in higher education instruction. CGU Theses \& Dissertations. Paper 39. doi: $10.5642 /$ cguetd/39

[41] Garrison, D. R., \& Kanuka, H. (2004). Blended learning: Uncovering its transformative potential in higher education. The Internet and higher education, 7(2), 95-105. doi:10.1016/j.iheduc.2004.02.001

[42] Levine, A. E. (2000). The future of colleges: 9 inevitable changes. The Chronicle of Higher Education, 47(9), B10. Retrieved from http://chronicle.com/article/The-Future-of-Colleges-9/10560

[43] Mott, J. D., \& Granata, G. (2006). The value of teaching and learning technology: Beyond ROI. Educause Quarterly, 29(2), 48. 